\title{
Trust, Distrust and Co-Production: The Relationship between Research Biobanks and Donors
}

\author{
Pascal Ducournau and Roger Strand
}

\begin{abstract}
This chapter addresses one so-called ethical aspect of biobanking, namely the relationship between biobanks for research and donors of human biological samples and personal health information. Central to bioethical theory and practice is the institution of informed consent and its potential to create trust. We present results from an observational study of the consent process during the recruitment to a local population DNA bank in Southern France as well as subsequent interviews with donors. Three types of donors were identified: (1) Persons holding a "natural trust" and who were quite uninterested in the information and consent procedure; (2) persons who expressed distrust, but nevertheless participated as donors; and (3) persons who appreciated the consent procedure as a sign of a well-organised institution. While informed consent may appear partly irrelevant to the issue of trust for a large group of donors, we proceed to discuss the status and desirability of a strong focus on donors' trust in biobank experts. Indeed, more symmetry and distrust may be a creative potential in the co-production of science and society in the biobank era.
\end{abstract}

\section{Introduction}

The construction of biobanks for research - collections of human biological samples or data emerging from such samples - has become a central element in contemporary medical population-based research. Different human entities, be it individuals, institutions or other forms of collectives, play different roles in biobanking. For instance, researchers and research institutions contribute with their skilful work and research infrastructures. Investors and funding agencies provide the financial basis of the frequently expensive research activities. Last, but not least, donors contribute with samples of their own body and often with personal health information as well. All three parties - researchers, investors and donors - are easily seen to be indispensable to biobanking. To some degree, their motivation for participating in the biobank venture may also have common features, such as the belief in the benefit for the community and for mankind that the biobanks are expected to generate through scientific and medical progress. On the other hand, there are obvious differences between the parties when viewed as stakeholders. Researchers may be employees, paid for their labour, or may hold other vested interests in the enterprise. Non-profit investors may have a defined mission to facilitate medical research on behalf of society, while commercial actors depend upon long-term possibilities of profitable products and services, mainly within medical technology. Donors, on the other hand, are not expected to receive other than symbolic economic benefits from their participation; indeed, in many countries the contrary would amount to illegal commerce with one's own body. In some cases, the donors are patients who could hope to benefit on an individual basis or collective level from the expected scientific advances in the treatment of their disease. Often, however, citizens will have no easily identified interest in being a biobank donor except for the altruistic motive. Accordingly, from the perspective of those who desire the construction of large biobanks for research (for instance governments and health authorities in many countries) a particular challenge is to ensure and uphold the citizens' willingness to act as 
donors and allow research on their donated biological samples and personal health information.

\section{The discourse of public trust}

Frequently, this challenge of recruitment is framed as a challenge of ensuring public trust in biobanks and population-based medical research, and donors' trust in particular (Hansson 2005; Tutton et al. 2004; Williams and Schroeder 2004). Furthermore, in the bioethics literature as well as in existing regulations, the information and consent procedures preceding the act of donation are seen as devices that may contribute to instil such trust. As such, this particular challenge may be seen in the light of a more general preoccupation in contemporary Western societies, namely the so-called "crisis of public trust" in science and expertise (as well as in the political elite). Episodes such as the socalled BSE scandal, the Bristol affair and the recurrent topic of the risk management of nuclear waste in the UK, and transfusions with HIV-infected blood in France, have played a crucial role in provoking such a crisis. Explanations of the crisis have been sought in institutional and moral deficiencies on the level of experts and authorities (such as in the mentioned "scandals") but also in public uneasiness about the production of risks (Beck 1992) and ethical problems in late-modern techno-society. A prime example of such uneasiness is seen in the European resistance towards genetically modified foods (Frewer 2003). Accordingly, both in biomedical research as well as in European scienceandsociety (FP6) and science-in-society (FP7) policy, a lot of attention is given to ensure accountability, transparency, ethical standards and proper risk management, with the aim of creating public trust, compliance and cooperation. In biomedical research, a primary strategy for achieving these objectives has been to implement informed consent practices and procedures.

In this chapter, we address two fundamental assumptions embedded in the argument about the importance of trust and trust-enhancing procedures in the context of biobank sample donation. First, we present empirical results that lead us to a further problematisation of the hypothesis that information and consent procedures build trust. This finding has normative consequences for the ethical regulation and design of biobanks: if the donors' trust is not obtained by consent and information procedures, such procedures are not necessarily sufficient to prevent irresponsible uses of data biobanks. Secondly, we challenge the appropriateness of framing the relationship between biobanks and their donors as a matter of ensuring trust. Indeed, we argue that such a framing reproduces asymmetrical relationships with respect to knowledge and power, relegating the donor to the role of the unknowledgeable and disempowered. In order to begin the work to overcome this deep asymmetry so characteristic of modern societies, the diverse research field dedicated to study the relationships between science, technology and society (STS) has moved towards a shared understanding of the necessity to study the three fields - science, technology and society - all as emerging out of the same large set of entangled social processes (Pickering 1995). In this sense, science and society are coproduced. This implies, however, that both scientists and citizens take part - directly or indirectly - in coproducing both science and society. Although scholars will disagree on the descriptive details and normative implications, the coproduction perspective has proved fruitful in its different forms (Callon et al. 2001; Funtowicz and Ravetz 1993). In the final parts of this chapter, we propose some initial steps on the way from a framework of trust to a broader perspective upon biobanking, taking into account the lessons learnt from STS studies. 


\section{What is trust?}

First, however, we shall need to provide some clarification of the concept of trust. In English, the noun "trust" has several usages. One dimension of trust is the nature of the relationship to its object, which may range from a reliance on moral or other qualities of a person or thing ("faith") to a pragmatic expectation of success or reward ("hope"). A second, highly important distinction is that between trust as a psychological state and trust as an organisational factor of human action. In both cases, trust can be described as an assured reliance on something or somebody. In trust as an individual psychological state, the reliance consists in a belief or a sensation. Trust as an organisational factor of human action, on the other hand, consists in a certain consistency of action, for example in the voluntary abstention from own critical judgement. Often, one would like to think that the consistency of action is caused by the corresponding belief, such as when the patient will follow the doctor's orders because he believes the doctor to know better than himself. Nevertheless, the relation between psychological and behavioural reliance is neither necessary nor necessarily simple. The consistency of action may be entirely due to strategic motives or even of a contractual nature, exemplified by the institutions of trust in the world of commerce. There is also the phenomenon that Wynne (1996) called virtual trust, in which there may be no spontaneous belief in the person or object to be trusted, but the alternative to trust appears psychologically or pragmatically intolerable: If there is only one doctor in the village, you have no other tolerable choice than to trust him. According to Wynne, sudden loss of public trust may be due to the prevalence of virtual over "real" trust.

When a person trusts another person or institution, it appears that we may identify a certain asymmetry of knowledge. Thus, on the psychological level, the trusting person is in an intermediary state between being knowledgeable and ignorant. If somebody knows everything about another person, he does not have to trust him but, if he does not know anything about the other, he has no reason to trust him (Simmel 1992). Likewise, there is an element of power structure in trust, as trust as an organisational factor of action means to partially abstain from exercising critical, autonomous judgements.

\section{Natural and obvious donor trust in biobanks and biobankers}

Biobanks for research pose a fundamental problem to the logic of individual autonomy and full information. It is simply impossible to predict the ultimate consequences of the research that will be performed on the data and the samples that have been collected. Research goals will change and surprises will appear, and uncertainty is a necessary dimension of biobanking as indeed of all research. Apparently, when the public give their samples and information, they have to base their decision on trust: they need to have hope in the biobanks and faith in the biobankers, much in the same way that we have faith in our banker's skills and honesty, and hope in the interest rate that the bank will be able to offer us.

It is in this context that the practical question emerges for those who operate the biobank: If donors' willingness to participate depends upon their trust, how are the biobankers to recruit and treat the donors in a trustworthy manner? A possible way to address the question of trust is to consider the procedure of informed consent. Indeed, in the literature informed consent is presented as a "ritual of trust" between biomedical 
actors and research participants or patients (Wolpe 1998).

One of us (Pascal Ducournau) has had the opportunity to conduct an empirical study of donors during the creation of a local population DNA bank in Southern France. Results from this study are presented and discussed in this chapter as well as in chapter 3. Methods and design have been described in detail (Ducournau 2005, 2007). Of special interest in this chapter is how a biobank donor group is formed (and later, how we were able to approach donors as informants to our study). Before turning to key findings, let us first review these recruitment processes.

In brief, donors were recruited by drawing of lots from electoral lists to build a control group study (but not only), in exchange for a cardiovascular health assessment. Another bank of the same type, not of the general population but of cardiovascular hospital patients, was also established and added to the first bank, to build a case group study. A total of 1800 adult males with age in a predefined high-risk interval were solicited in either case, of which around $40 \%$ accepted to participate. The objective of the biobank project was to study interactions between genes and environment in the occurrence of cardiovascular disease and to investigate possibilities for new genetic tests allowing better predictions and prevention.

In order to obtain their consent, the recruited persons were asked to read an information sheet about the study, and if necessary, to ask questions, and then to sign a one-page information and consent form. By giving their consent, they were assumed to confirm that they had evaluated and accepted the consequences of participating in the study. The aim of the consent procedure can accordingly be described as an incentive to act, making a rational assessment of the participation, including possibilities to talk with the physician recruiter followed by the construction of a deliberate individual choice. This procedure has been characterised as putting the person in a new role with respect to medical solicitation: a self-overseeing actor of the uses of the body and its elements (Memmi 2001). In the information sheet it was stated that the collected data would be used only for the objectives presented (the study of cardiovascular pathologies) and that the results of the genetic analysis would not be broken down to the level of individual DNA samples. Consequently, it was emphasized that the participants would not obtain individual results about their genome. Finally, in the information sheet it was stated that participation in the study would not entail any risk for the participants, except for the negligible risk connected to the letting of the blood sample:"Your participation in the study does not involve any particular risk. The blood test corresponds only to the taking of standard blood test".

Guarantees of anonymity and data confidentiality were given in the information sheet, and the potential participants were also informed that the study had been approved by the relevant ethics committees.

One of us (Ducournau) had the opportunity, following negotiation with the research team and the local ethics committees, to observe the signing of the consent form and then to have an interview with 61 participants in the days following their entry into the study. The semi-structured interviews were designed to allow participants to talk about their motives for participation and to give their account and point of view on the form of the consent device and procedure (the signature ritual in particular) and also on the content of the information presented to them. The interview material was interpreted in terms of the 
degree and nature of the endorsement. For instance, whether the participant read or not the information sheet, or asked questions, was considered interesting information in this respect.

A major finding was that approximately a third of the participants took on a strongly delegative role, leaving the question of the decision and of the understanding of the objectives of the study in the hands of the doctors and researchers. Thus, when presented with the informed consent device, supposed to give the individual the role of an "informed rational decision-maker", the participants responded with a logic of cooperation. This manifested itself in two types of attitudes: (1) They explained their own decision as ensuing from the advice of doctors and researchers, and (2) they conceived of the consequences of the action as beyond their knowledge and understanding. Hence, one participant explained:

"I haven't read it (the information sheet) because if you considered it useful to go through, there was no problem, I agreed to it [...]. When she [the doctor] told me to participate in it, I did so [...] and I said to myself, if she does this, it is because she has a good reason [...] what sense will it make for me to know what it will be used for [the DNA]; I thought it could be useful to help research, to improve the treatment possibilities of coming generations of doctors, [...]. If they do this, they must have a reason. I think for them the reason for performing this study must be that it is cardiovascular disease". Question: "And you didn't try to get more information?" Answer: "When you choose to trust somebody, you simply do so. If you get killed, that's a pity. Anyway, you have to trust if you want to be treated".

In the discursive exposition of these delegative attitudes concerning the knowledge and the decision that catch the consent device on the wrong foot, we identified conceptions of the production activity of the medical and scientific knowledge. These conceptions were strongly marked by ideas of division of labour and an expert/layman asymmetry that is particularly visible in the lacking desire to be explained the aims of the research. There is, on the one hand, what is "useful" to know for the lay participant, and on the other hand, what is "useful" for the biomedical actors. The "not-trying-to-know" attitude can also be interpreted as a real disinterest. Then, a feeling of trust toward "medicine", "public research" (as opposed to private research) or researchers can be mobilised in this non consideration of the medical and scientific objectives of the study for which the persons have been solicited. Indeed, trust allows for a kind of "cognitive economy" (Grossetti 2004) since it leads the doctors and researchers not to linger on the consequences of the action, not to "lose oneself" in various speculations; it allows the decision to be built on uncertainty. The participant does not know the objectives of the research but has faith in the researchers:

"Not knowing what this research is for, I don't really care [The information sheet], it's too long to read. [...]. For sure, I have asked if, for me, it could lead to any sort of discomfort... That's my concern. If they had asked me to take medication and then come back every month, I think I would not have agreed [...] I will not go to the bottom of things to find out whether what I think of genetics is right or entirely wrong. There are doctors, they are here for that, that's what I think. Thus you trust them or not. [...]. Trying to be enlightened is a waste of time. It doesn't lead to anything. [...] I'm a good participant. I don't ask questions [...] I have done mine, after that, the doctors, the researchers have to do the rest". 
Our findings about natural trust are consistent with the extensive study of donors in the Swedish Umeå Genomics biobank (Hoeyer 2003; Hoeyer et al. 2004, Hoeyer et al. 2005; Hoeyer 2006),58 in which the donors were portrayed as not much interested in the consent form and the specific information they were given, nor at all knowledgeable of the biobank and its research after donation. Indeed, their attitude was summarised in the title of Hoeyer (2003): "Science is really needed - that's all I know", and, we may add, all they needed to know to make their decision to participate. The findings lead us to the concept of donors' relatively wilful ignorance (Michael 1996) of the objectives of the study. Wilful ignorance appears generally not to be considered in biomedical ethics where the degree of understanding of the protocols by the lay persons rather appears to be interpreted in terms of a more or less implicit "deficit model", envisaging the need for increased "enlightenment" of participants by educational means (Annas 2001; Moutel et al. 2001).

\section{When natural trust is missing: distrust and virtual trust}

In contrast to the participants who did not take into account the medical and scientific objectives of the research, we found a different group of participants (less than $25 \%$ of the participants) who questioned the purpose of genetic research in general as well as the objectives of the study for which they had been recruited in particular. They had various reactions regarding the consent form and procedures, and notably also with regard to the signature procedure of the consent form. Far from seeing this as a ritual of autonomy or freedom of choice, they claimed to reveal in the consent form and the implicated procedures a way of eventually constraining the participant, in the sense of them having "no possible resort afterwards" if things "turned out badly", or a way for the biomedical agents to "unload themselves of all sort of consequences" by saying "nobody forced you" (Ducournau 2005, 2006). The information given on the aims and objectives of the study did not satisfy these participants' expectations. This group of participants did not share the conception of the laymen/expert relationship presented above, that is, in terms of fundamental asymmetry and division of work. They said for example that they had taken the opportunity to participate in genetic research to involve themselves in a domain that they did not want to leave to the specialists:

"I said to myself: if I don't participate, I do not give my consent, in saying what I have to say, my thoughts will not be translated" (A participant who commented on the risks and uncertainties of genetics to the recruiting doctor).

These participants may remind the reader of Ulrich Beck's concept of the "modern distressed consciousness". They develop their own thinking about the risks of technoscience. The doubts and mistrust of these participants are articulated around issues such as respect for the confidentiality of the data stored in the bank, the "filing information" and the genetic manipulations, the cloning, the eugenics and the use of research - the aim of which could be a commercial one. In these ways of questioning, the rational assessment of the consequences of the action gets concerned with the medical and scientific rationality itself. Rationality thus enters a "speculative era" on risks, on what cannot be seen, an era in which the modes of thought and representation of their connection in the visible world get loose (Beck 1992).

Illustrative of such a view is the following account by one of the participants of the 
moment when he received the information note:

"One understands while reading the letter that as a matter of fact, there's a taking (of blood) and that a bank of genes will be set up. However, the presentation in the letter is quite unclear and the explanations given by the doctor present are unclear as well, which gives reasons for doubt: how will this sample be used? It's a bit difficult to understand how the DNA will be used: whether it is for long-term use or, well, what is the intention behind storing it ... One gets the impression that it is a bit like science-fiction; [...] one wonders what can be done with this material, what could be imagined... And imagination runs easily... since we have these stories of cloning, manipulation and so on".

Furthermore:

"They cover themselves by saying I gave the authorisation. I am talking about medicine, and science...they are safe since I accepted. But I have accepted only on one condition: that it does not leave its medical environment. But here, I have in fact no proof [...] of the travelling of my DNA".

One noteworthy fact is that these participants, in spite of their doubts and mixed feelings, did not refuse to give their consent. This finding is similar to Hoeyer's (2006) report of donor worries. Different reasons might explain this phenomenon. First, for some of these participants, facing the perceived impossibility to understand fully the aims and workings of the study, there was no other choice than to trust the biobankers. Trust represents then the only possible alternative to refusal (which they did not choose), but the kind of trust involved appears to be reminiscent of Wynne's conception of virtual trust. Second, and possibly complementarily, a refusal to participate could lead to a stop of the research itself, with an implied risk of generally stopping progress. Compliance appears here also as the preferred option, not the least for the persons who need new medical therapies (in the case group study for example). This situation is reminiscent of what Ravetz (2001) denoted as a "safety paradox": The research might be unsafe or have unknown and unwanted consequences or aspects, but the alternative might be even worse.

\section{The group between}

Between the first group of participants who were cooperating in a delegative way and the second group of relatively distrusting participants, a third group (approximately $1 / 3$ of the interviewed participants) actually appeared to use the informed consent procedure as a "ritual of trust". The information provided in the information sheet, the consent form and the dialogues with the physician were utilised by these participants to explore the aims and workings of the study and were found sufficient to allow them to cooperate without any distress. One might say that they used the consent "device" as expected by legislators and ethicists: reading the information sheet, listening to the oral explanations and asking questions. For some informants, the information and consent procedures were described as a "contract" process producing trust with a procedure of signature that presents finally the rights and duties of each party involved in the project. However, their trust in the biobank project was not only generated by the procedure of consent. Trust was perceived as the result of a combination of different elements. A reference to Durkheimian sociology may help to explain this point: "All is not contractual in the contract" (Durkheim 1893/1930: 189). By this sentence Durkheim wanted to underline that a 
contract must be accompanied by moral involvement to be really effective. If the contractors do not respect the duties entailed in a contract, the contract cannot organise social relationships. All the contracts could be broken and any suitable relationship could be generated by a contract frame. A necessary condition for a successful outcome of a contractual relationship is located outside the contract, in the moral involvements of the parties to respect the contractual clauses. This is why a contract can work, and why it can constitute a basis for some social relationships. A parallel can here be drawn between Durkheim's analysis and the construction of trust by the procedure of consent. If the consent procedure is necessary to create trust between the parties, it is not a sufficient condition. Macro-social conditions as trust in political, medical and scientific institutions are needed for making the interaction around the consent procedure work. The ritual of trust works if the donors have trust in the institution that is soliciting them:

"They make us sign this paper for our consent for the DNA research, yes! Even so it is quite confidential, DNA, isn't it? Well... They penetrate the core of your intimacy since one knows who you really are... So I suppose that is why they make us sign this paper [...] Personally, I had no need to sign this paper; they could take the DNA, as much as they wanted. But well, since they ask you, you see that the procedure is a serious one: well, they take precautions. It confirms the idea of the seriousness of the examination".

So, why did this participant say: "It confirms the idea of the seriousness of the examination "? In another part of the interview he explains that it is needed "to make trust in medicine" and that the public research institution involved in the project is a serious one. Obviously, trust is the result of the combination of different elements where the consent procedure is not the only one, and where there exist structural factors of trust as the trust in the experts of medical research and their institutions.

In another interview, the participant underlined the contractual dimension of the consent device and its power to reduce uncertainties in the relationship:

"I signed an agreement to do certain things. This agreement was using some pieces of information that I read in the mail notice I received, the agreement for the DNA sample etc, all the things that a citizen can legally verify or refuse concerning the exams that were made. There is no mystery; [...] It is a normal action to sign a form. This can be used as a discharge for them if there is a protest. This is a reciprocal contract. [...] This is a contract that says to me: we do not have to communicate the results of the DNA tests, and if you want you can ask the destruction of your DNA samples".

We can observe here that trust in the biobank project is also constructed in relation to a more general trust in the juridical and political system of respecting the rights of the "citizens".

In the three described groups of participants, trust appears then as a fundamental element in the construction of their co-operation. But the origin of this trust cannot be located in the consent and information procedures of the biobank recruitment. For the first group, there was too little attention paid to the information sheet and consent form to see the trust as derived from them. Trust pre-exists. The particular "research contract" presented to these participants gained its very importance through the "general contract" 
they mobilized with medicine, institutions and society: they believed in medical and scientific progress, in the responsibility and the expertise of public medical institutions. For the second group (the distrusting donors), trust did not appear in the same way, as resulting from the procedures of information or consent. On the contrary, these procedures were perceived as creating conditions of mistrust, and virtual trust appeared and was enforced upon them because of a lack of viable options. For the third group, i.e. the group in-between, trust was perceived more as constructed by the information and consent procedures provided, but it could not be reduced to these procedures, because macro-elements of trust played a role as well, such as trust in the expert and political institutions.

\section{Trust, distrust or co-production: towards an alternative design of biobanks}

The interview study presented above leads us to question the standard way of designing biobanks as organisations, and provides us also with some normative ideas for alternative designs. As explained in the introduction to this chapter, from the perspective of those who encourage, facilitate or perform the creation of large biobanks, it may seem important to ensure and uphold public trust - in particular donor trust - in the biobanks and the research they are meant to serve. From such a perspective, there is little doubt that biobanks are considered to represent something good, in ethical as well as political terms, but the inherent uncertainty in scientific research makes this goodness difficult or impossible to demonstrate beforehand. To the extent that the donors are not familiar with the workings of science, they accordingly have to trust the experts.

In the empirical part of this study, a majority of our informants indeed expressed such a trust. For a third of the informants the quality of the trust is what we have called "natural": It is a general trust in public medical research and the medical profession, and, as pointed out in Hoeyer and al.'s studies of Umeå Genomics, perhaps also a trust in local health/research personnel and local control and oversight. This trust appears to be in place before the information and consent procedures start. Indeed, in our data there are clues to support the speculation that the information procedure may decrease or at least disturb this natural trust by implicitly communicating that the donor ought to assimilate and critically assess technical information concerning the biobank. It should be remembered, though, that it is difficult to know how the donors would have reacted to the absence of any information and consenting procedures. The mere fact of its presence may give assurance, irrespective of how uninterested the donor may be in the specific details. Nevertheless, from our data we find it difficult to describe the information and consent procedures as a "ritual of trust" as Wolpe (1998) did. Rather, the information and consent procedures could be called a ritual of autonomy and contract, imposing a contractual relationship between biobank and donor.

One of the normative key questions addressed by the donors' natural trust in the organisational design of research biobanks is the ability of biobanks to deal responsibly with this kind of trust. In this case, consent and information procedures do not provide ethical guidance because trust is given a priori. In the imagined case that the goals of the biobank project are ethically irresponsible or contestable, the naturally trusting part of the public might not pay any attention, not even if the irresponsibility of the goals is revealed in the information sheet. At best, biobankers may be sufficiently responsible to take account of this natural trust by assuming the moral duties of a trustee, though this is not obvious, as discussed by Williams and Schroeder (2006). At worst, they can use the consent and information procedure as a way to dissipate their sense of responsibility 
(Hoeyer 2006). Equally challenging, the biobankers may be unaware of ethical aspects that are contested in society in general or in academic discourse, aspects which in that case will be considered neither by biobankers nor by donors.

\section{Efficiency or empowered citizenship}

Several normative interpretations may be made from the possibility that the information and consenting procedures erode natural trust. In the official policies of many, if not most, countries research biobanks and biomedical research on the whole are seen as beneficial and desirable on a societal level. From this perspective, one might conclude that even though autonomy on behalf of the donors should be secured through informed consent procedures, natural trust is highly desirable in order to achieve efficient enrolment of donors. Indeed, for those who believe strongly in the value of large biobanks and at the same time believe themselves to be experts who ought to be trusted, one might fear that the loss of natural trust might cause lay people to be "led astray" into irrational forms of distrust.

On the other hand, in particular in the European Union there is an increased of biological material and associated information data: "biobanks", "biolibraries"). attention to the development of democracy and empowered citizenship in a knowledgebased society. From this perspective, one might see natural trust as naïve and undesirable, as something that reproduces the asymmetrical relationship between lay and expert and should therefore be overcome. Indeed, in the current policy of the European Union (FP7 Science-in-Society), the coproduction perspective is to some extent present. This document recognises that long-term scientific advance is unlikely without the support of knowledgeable, empowered citizens, and perhaps also undesirable without this support. Accordingly, one might emphasize the value of enlightened democracy and the importance of the citizens themselves in defining progress and societal benefit, at the cost of smooth and efficient enrolment of donors in the short-term perspective.

\section{Switching from trust via virtual trust to distrust}

Part of the nature of natural trust, however, is that it may enter into dialectic with powerful changes between trust and distrust. Such episodes are known not only from recent scandals mentioned above involving scientific experts, but more generally from our political history, such as the collapse of the former Soviet Union. We may hypothesize that such switches may happen more dramatically in cases of virtual trust or other forms of strongly asymmetrical trust relationships. Thus, even from a strategic probiobank perspective it may appear appealing to avoid a strong reliance on natural trust, which might flip or disappear in an unpredictable manner.

Distrust may be grounded in many ways. Our empirical data share the methodological weakness of many studies that our informants have accepted to participate in our study; and in our case, they actually also accepted to donate samples to the biobank. What we observe, however, is the apparent unproductiveness of the information and consent procedures in dissolving distrust. Rather, the procedure is taken to be a part of the system that is the object of distrust, a system much more broadly defined than the "biobank" or the particular research institution or team of researchers. As noted by Frewer (2003), although criticism of biotechnology may be presented in 
terms of risks and ethical challenges, its foundation can be a difference in value systems and fundamental forms of political disagreement. Critics of S\&T development may see it as part of an accelerated, unsustainable capitalism and a run-away train, possibly producing monstrosities and misery in the long-term perspective. In this perspective, the information and consent procedures are offering anything but assurance. On the contrary, they may be seen as a confirmation of researchers and the "system" having a too narrow scope in what they consider relevant information, not seeing, or not wanting to see, that they play a part in the global problems.

Hence, the participants are led to give their approval inside a predefined scope which has never been the subject of a previous discussion. As Cresson recalls (2000), in the much more general scope of the medical contract it is the doctors who generally give the definition while no attention is given to what definition that the patients would give. The analogy to our case of DNA banks is clear. If the ethical committees approve of the protocols and the consent procedures used, and consent in this way constitutes a mediation between researchers and donors, the latter have little opportunity to intervene themselves in the definition of the scope in which they are asked to consent. Furthermore, by signing the consent form the donor has forfeited his possibility to oppose the framing of the problem. Still, our informants signed the form, which indicates the complexity of beliefs and sentiments that the individual may hold: trust, distrust, sense of duty, curiosity, or perhaps, for some of them, all at the same time.

\section{From trust to co-production}

We have argued that a model of biobank-donor relationships based on trust may in part reproduce undesirable power and knowledge asymmetries, and in part may be quite unpredictable as trust may lead to distrust. It remains to investigate if trust partially or wholly could be replaced by types of relationships in which the donors delegate less and participate more, and to what extent this would be desirable.

A first observation in this respect is that one should not speak in an unqualified manner about what is "desirable" without also asking "desirable for whom?" The authors of this study should not be viewed as advocates of "the citizens" or "the donors". As has already been argued, they are a heterogenous group with different opinions on biobanks. Rather, one should situate the perspective of the present analysis as de facto remaining in the academic discourse surrounding the regulatory issues of research biobanks. In this respect, "desirable" means "desirable in terms of the regulatory perspective". However, in this analysis, it is important to maintain an agnostic and critical distance to unconditional beliefs in the benefits of research biobanks and the importance of the efficient enrolment of donors to them. These beliefs, however predominant in current health policy discourses in Europe, do not form a necessary part of the regulatory perspective. Rather, they depend upon more general ideological beliefs in progress and science. Such beliefs need to be problematised both for intellectual and pragmatic reasons (Nordmann 2004).

In order to maintain the required analytical distance, we propose to consider a transition from the analytical framework of trust to that of co-production. The analytical framework of trust tends to frame thought in the categories of the experts and the lay people; knowledge and the unknowledgeable; information and the uninformed etc. A discourse of trust appears to assume a belief in the possibility of knowing in principle 
what is correct and what is good at the time of making the decision. This is less relevant, we believe, in contexts characterised by essential unpredictability and uncertainty, something which, in our view, is the case with biomedical research in general and research biobanks in particular. It is impossible to be "informed" in the classical sense because the future of the research is not determined at the time the material is collected. It is the future that determines its use.

The analytical concept of co-production (as originally introduced by Jasanoff and developed by Latour and the tradition of actor-network theory) was designed to be less myopic with respect to the study of science, society and the interface between them. A discourse of co-production allows us to consider a broader range of relationships between biobanks and donors. As explained above, such a consideration will not necessarily be seen as desirable, interesting or even relevant by all actors in the discourses of the regulatory issues of research biobanks. We think, however, that two (interrelated) issues may profit from an analysis from a perspective of co-production. First, there is the possibility that trust is ineffective and insufficient, and collapsing into distrust, as explained above. Second, there is a need for paying more attention to the aspect of unpredictability of the future of research and its implications for society. We shall argue that both issues may call for co-responsibility if broader attention is given to the actual and possible roles of donors and citizens in general in science, as well as the actual and possible roles of scientists in society, along the lines of analyses into social robustness of knowledge (Nowotny et al. 2001), post-normal science (Funtowicz and Ravetz 1993) and more generally the literature on governance of science and technology.

Callon and Licoppe (2000) argue that when scientific actors are on an equal footing with the public actors, trust is not necessary because the different persons who are involved in the interactions are not in asymmetric positions. Groups of HIV patients, persons with myopathies, are in France involved in this new kind of scientific and biomedical production of knowledge. They participate actively in the definitions of goals and modalities of research. For Callon and Licoppe, there is not in our contemporary society a crisis of public trust in science but an evolution of the organisation of research, that is including more and more "expert lay people".

A large and unsolved question is how, in practical terms, the more participatory approach could be achieved in the case of research biobanking. The few empirical studies of such attempts appear to conclude pessimistically about the prospects of real participation with a less than strongly asymmetric expert-donor relationship (Reardon 2001; Tupasela 2007; Tutton 2007). A possible beginning would be to invite participants to cooperate with biobankers in the design of the information and consent procedures, allowing new devices, possibly on the group or community level, for the debate of broadscoped issues, including the societal and technological significance of the biobank. This beginning would not be enough, however, because the broader debate would probably identify a number of unsolved issues regarding the uncertainties of the implications of the research and regarding values and stakes in conflict. For instance, potential donors may disagree with research priorities or with the anticipated model of technology transfer in the case of commercially viable results. They might even disagree with the methodological design, perhaps arguing that more (or perhaps less) psychosocial variables should be integrated with the biological information. One might imagine donors to organize and negotiate their priorities with the research institution and the investors; and one could imagine scientific boards in which donor representatives act to promote the 
translation of their ethical and societal priorities into methodological design and the daytoday research practice. This would amount to a case of what has been called "postnormal science" (ciencia con la gente) (Funtowicz and Ravetz 1993). Such an empowerment of the public would almost necessarily imply a reduction of the power of investors, central authorities and the research sector as they appear today, that is, often in mutual agreement and without too much intervention by the people. We say "almost necessarily", because if trust turns into distrust, the resulting lack of cooperation might disempower all parties.

The second large question is what society would gain from such an approach, and if and when it would be desirable. Indeed, it is hard to see that a democratization of science could be defended purely on its own terms and in conflict with scientific efficiency and quality. This is where the intellectual strong points of the co-production perspective need to be called upon, because it explicitly sees science and other parts of society as inextricably intertwined. Central in the theory of post-normal science is the demand that participation should be a means to heighten the quality of research, above all by increasing its relevance. We may interpret the case of myopathy and HIV patients in this way: Research and hence knowledge is improved by opening up methodological discourses in order to increase the relevance. In that case, it would be a matter of tailoring the objectives and hence the design of research to the needs of the patient groups. More generally, there is also a need to improve our civilisatory abilities to avoid the unintended and harmful effects of scientific research and knowledge, resulting from scientific research being essentially unpredictable and open-ended (Pickering 1995). In the terminology of Nowotny et al. (2001), knowledge needs to become socially robust.

There is at present no methodology to predict the unpredictable, and possibly will there never be. This does not mean that society cannot develop strategies by which we attend the unpredictabilities and uncertainties of research in a more responsible way. In such strategies, imaginative and critical thinking might play a key role. Indeed, with more attention given to "creative sceptics" some of the adverse effects of science and technology might have been avoided or limited (Harremoës et al. 2001). It strikes us that the group of informants characterised by virtual trust and distrust display imaginative critical thinking. Hence, without imposing the model of co-responsibility on each and every donor, from a regulatory perspective one may see sceptical and distrusting citizens as a particular intellectual resource in the struggle to elaborate good pathways of the coproduction of science and society. 


\section{References}

Annas GJ (2001) Reforming Informed Consent to Genetic Research. Journal of the American Medical Association 286:2326-2328

Beck U (1992) Risk Society. Towards a New Modernity. Trans. from German by Mark Ritter, and with an Introduction by Scott Lash and Brian Wynne. Sage Publications, London

Callon M, Licoppe C (2000) La confiance et ses régimes: quelques leçons tirées de l'histoire des sciences. In: Laufer R, Orillard M (Eds.) La confiance en question. L'harmattan, Paris, pp 133-154

Callon M et al. (2001) Agir dans un monde incertain. Essai sur la démocratie technique. Seuil, Paris

Cresson G (2000) La confiance dans la relation médecin-patient. In: Cresson G, Schweyer FX (Eds.) Les usagers du système de soins. Editions de l'Ecole Nationale de Santé Publique, Rennes, pp 333-350

Ducournau P (2005) Le consentement à la recherche en épidémiologie génétique: un rituel de confiance en question. Sciences Sociales et Santé 23:5-36

Ducournau P (2007) The viewpoint of DNA donors on the consent procedure. New Genetics and Society 26:105-116

Durkheim E (1930) La division du travail social. Presses Universitaires de France, Paris 
Frewer L (2003) Societal issues and public attitudes towards genetically modified foods, Trends. Food Science \& Technology 14:319-332

Funtowicz S, Ravetz J R (1993) Science for the post-normal age. Futures 25:739-755

Grossetti M (2004) Sociologie de l'imprévisible. Dynamiques de l'activité et des formes sociales. Presses Universitaires de France, Paris

Hansson MG (2005) Building on relationships of trust in biobank research. Journal of Medical Ethics 31:415-418

Harremoës P et al. (2001) Late lessons from early warnings: the precautionary principle 1896-2000. Environmental issue report No 22. European Environment Agency, Copenhagen

Hoeyer K (2003) "Science is really needed -that's all I know": informed consent and the non-verbal practices of collecting blood for genetic research in northern Sweden. New Genetics and Society 22:229-244

Hoeyer K et al. (2004) Informed consent and biobanks: a population-based study of attitudes towards tissue donation for genetic research. Scandinavian Journal of Public Health 32:224-229

Hoeyer K et al. (2005) The ethics of research using biobanks -Reason to question the importance attributed to informed consent. Archives of Internal Medicine 165:97-100

Hoeyer K (2006) The power of ethics: a case study from Sweden on the social life of moral concerns in policy processes. Sociology of Health \& Illness 28:785-801

Memmi D (2001) Surveiller les corps aujourd'hui: un dispositif en mutation? In: Sfez L (Ed.) L'utopie de la santé parfaite. Presses Universitaires de France, Paris, pp 173-184

Michael M (1996) Ignoring Science: discourses of ignorance in the public understanding of science. In: Wynne B, Irwin A (Eds.) Misunderstanding Science? The Public Reconstruction of Science and Technology. Cambridge University Press, Cambridge, pp $107-125$

Moutel G et al. (2001) Bio-libraries and DNA storage: assessment of patient perception of information. Medicine and Law 20:193-204

Nordmann A (2004) Converging technologies - Shaping the Future of European Societies. Report for the European Commission via an Expert Group on Foresighting the New Technology Wave. European Commission, Brussels

Nowotny H et al. (2001) Rethinking Science. Polity, Cambridge 
Pickering A (1995) The Mangle of Practice. The University of Chicago Press, Chicago

Ravetz J R (2001) Safety paradoxes. Journal of Hazardous Materials 86:1-16

Reardon J (2001) The Humane Genome Diversity Project: A Case Study in

Coproduction. Social Studies of Science 31:357-388

Simmel G (1991) Secret et sociétés secrètes. Circé, Paris

Tupasela A (2007) Re-examining medical modernization: framing the public in Finnish

biomedical research policy. Public Understanding of Science 16:63-78

Tutton R (2007) Constructing participation in genetic databases - Citizenship, governance, and ambivalence. Science, Technology \& Human Values 32:172-195

Tutton R et al. (2004) Governing UK Biobank: the importance of ensuring public trust.

TRENDS in Biotechnology 22:284-285

Williams G, Schroeder D (2004) Human genetic banking: altruism, benefit and consent. New Genetics and Society 23:89-103

Wolpe PR (1998) The Triumph of Autonomy in American Bioethic: A sociological

View. In: DeVries R and Sudebi J (Eds.) Bioethics and Society. Prentice Hall, Upper Saddle River, pp 38-59

126 
